\title{
Polychotomous or Polytomous?
}

\author{
David J. Weiss \\ University of Minnesota
}

I grew up on polychotomous. Throughout my graduate training (I don't believe that I knew the word before that), Likert scales were referred to as an approach to measuring attitudes that used polychotomous rather than dichotomous items. Likewise, a multiple-choice item could be scored either dichotomously or polychotomously.

The first time I encountered the word polytomous was about ten years ago (after about a quarter of a century of exclusively using polychotomous). It was in a manuscript that I was editing for $A P M$ that had been written by an author in Europe from a country in which English is not the first language. Being a conscientious editor, I assumed that this European had obviously made an error with the use of English and dutifully changed all the polytomous to polychotomous. As usual, I sent the manuscript to the author for review before it was typeset. When the manuscript came back from the author, all the polychotomous had been carefully changed back to polytomous -and the author included a brief note saying that the latter term was correct and that they meant the same thing.

Of course, being a typical American I assumed that this person who spoke another language was wrong, and I went to my big Webster's International Dictionary (Neilson, Knott, \& Carhart, 1961) to prove it. Much to my amazement, I found both words with the same definition, although they have different origins. Polytomous (p. 1915) is used primarily in botany, and polychotomous (p. 1911) appears to derive from biology.

When we began planning this Special Issue I knew that both words would be used and felt the need for standardization, so I queried the authors for their preference. Again, I received a lesson in English from a European from another country in which English is not the first language. Gideon Mellenbergh (personal communication, January 17,1995 ) indicated:

The word "dichotomous" stems from the contraction of the Greek "dicho" $(\delta i x o=t w o)$ and "tomous" ( $\tau 0 \mu \rho \sigma=\mathrm{a}$ cut). The word "polytomous" is a contraction of the Greek "polus" ( $\pi 0 \lambda u \sigma=$ many) and "tomous." Therefore, the correct contractions stemming from Greek are "dicho-tomous" ("two-cut") and "poly-tomous" ("many-cut").

My dictionary, of course, confirmed this and further indicated that polytomous and dichotomous are opposites of each other (Neilson et al., 1961, p. 1915). As a result, polytomous is used in this Special Issue and will become the standard usage in APM; polychotomous will be laid to rest, except when it slips out by habit in my class lectures and conversations.

Who said that Americans have nothing to learn from Europeans?

\section{Reference}

Neilson, W. A., Knott, T. A., \& Carhart, P. W. (Eds.).

(1961). Webster's New International Dictionary of the
English Language (2nd ed., Unabridged). Springfield MA: G.C. Merriam Company. 